\title{
Implementation of the Sprint Design in the Design of Prototype Islamic Crowdfunding for Women-Owned MSMEs
}

\author{
Retty Isnawati ${ }^{1}$, M.Ruslianor Maika ${ }^{2}$ \\ rettyisnawati.umsida@gmail.com¹,mr.maika@umsida.ac.id² \\ Universitas Muhammadiyah Sidoarjo, Jl.Mojopahit No.6660 B Sidoarjo Jawa Timur 61271
}

\begin{abstract}
The existence of a funding gap from investors and information on specific financing needs for women MSMEs encourages researchers to design a platform in the form of a crowdfunding platform specifically to address the gap between women MSMEs and investors. For this reason, researchers created a prototype Islamic crowdfunding design for women entrepreneurs by using the sprint design method. The purpose of this study is to find out how the implementation of the sprint design method in the design of the Islamic Crowdfunding prototype design to support women's MSMEs in Indonesia in helping to gain access to capital. This method is a method for building product concepts and prototypes within 5 days using this method can create a flexible product design framework, serves to maximize opportunities in making something that is desired.
\end{abstract}

Keywords: Women's Entrepreneurship, Islamic Crowdfunding, Design Sprint

\section{Pendahuluan}

Dunia saat ini percaya bahwa mendukung wirausaha perempuan sangat penting untuk pertumbuhan ekonomi. Namun, mayoritas wirausaha perempuan di negara berkembang mengahadapi masalah yang sama yaitu kurangnya keuangan [1]. Permintaan kredit yang belum terpenuhi terbesar berasal dari wanita, menciptakan produk keuangan yang dirancang khusus untuk wanita adalah situasi yang saling menguntungkan [2]. Hasil penelitian yang dilakukan oleh Pricewaterhousecoopers tahun 2017 menunjukan dinamika yang kuat dalam sebuah kampanye seed crowdfunding, dimana $32 \%$ project perempuan lebih sukses dari pada laki-laki. Selain itu, rata-rata penempatan dana pada projek crowdfunding perempuan setiap pendanaan terkumpul sebesar 87 dolar sedangkan yang laki-laki hanya memeroleh 83 dolar[3]. Crowdfunding sendiri sangat cocok untuk dilaksanakan karena lebih mudah bagi pemrakarsa proyek, terutama pagi masyarakat yang belum bankable, termasuk bisnis pemula[4]. Apabila crowdfunding membawa karakteristik keuangan Islam mampu memberikan dasar untuk perkembangan baru di lapangan, karena dapat menggunakan keuangan Islam sebagai alat yang bertanggung jawab secara etis dan sosial untuk mempromosikan pembiayaan dan pembangunan[5].

Peran gender dalam industri keuangan beberapa tahun terakhir, mendapat banyak perhatian dalam pers dan diskusi publik. Perusahaan modal ventura menyatakan bahwa mereka enggan untuk berinvestasi ke perusahaan rintisan yang didirikan perempuan[6]. Adanya gap pendanaan dari investor dan informasi kebutuhan pembiayaan yang spesifik untuk UMKM perempuan[7]. Hal ini mendorong peneliti untuk merancang sebuah wadah berupa platform crowdfunding khusus untuk mengatasi gap antara UMKM perempuan dengan para investor dengan menggunakan metode design sprint. Metode design sprint adalah suatu metode untuk membangun konsep produk dan prototype melalui lima tahapan dalam waktu lima hari, termasuk dalam penciptaan beberapa fitur untuk sebuah website lama. Design Sprint pada dasarnya digunakan untuk menyelesaikan permasalahan melalui desain secara cepat.

\section{Metode Penelitian}


Penelitian ini menggunakan metode penelitian kualitatif dengan pendekatan design sprint. Data yang diperlukan untuk penelitian ini dari sumber sekunder yaitu terdiri dari buku, artikel penelitian, proyek penelitian yang diterbitkan, laporan, berbagai situs web, jurnal dan surat kabar.

\section{Pembahasan}

\subsection{Tahap Understand}

Peneliti menganalisis data dari 113 fintech lending di Indonesia yang telah terdaftar di OJK (Otoritas Jasa Keuangan). Memaparkan bahwa fintech lending yang segmentasinya khusus ditunjukkan pada pelaku UMKM perempuan masih terdapat satu entitas. Namun, dari entitas tersebut platform fintech lending hanya berfungsi untuk para investor dalam menyalurkan dananya kepada pelaku UMKM perempuan. Jadi fintech lending tersebut belum dapat berfungsi secara langsung kepada pelaku UMKM perempuan dalam melakukan penggalangan dana pada platform. Melainkan apabila pelaku UMKM perempuan membutuhkan tambahan modal, pertama yang harus dilakukan adalah mencari pihak-pihak lapangan dari platform tersebut. Akibatnya, semua pelaku UMKM perempuan tidak dapat terbantu dengan baik dalam hal memperoleh akses permodalan secara langsung. Konsep seperti ini, menurut pengamatan peneliti masih kurang efektif dalam memberikan sarana akses layanan kebutuhan modal untuk pelaku UMKM perempuan. Maka dari itu peneliti melakukan diskusi dengan beberapa kelompok studi penelitian untuk mengetahui kendala dan masalah yang sering ditemukan terkait pinjam-meminjam di lingkungan UMKM milik perempuan. Ternyata sistem pinjam-meminjam yang saat ini diterapkan oleh perusahaan fintech masih belum dapat memenuhi kebutuhan pelaku UMKM perempuan. Sehingga diperlukan sebuah skema yang adil dan aman dalam akses permodalan pada UMKM milik perempuan. Seperti halnya keuangan islami ideal sebagai cara alternatif pembiayaan berdasarkan standar etika dan tanggung jawab sosial, yang memastikan distribusi yang adil dari manfaat dan kewajiban antara semua pihak dalam transaksi finansial[8].Islamic Crowdfunding mampu memberikan solusi terkait masalah permodalan para wirausahawan perempuan yang lebih tepat[9]. Dari beberapa pemaparan tersebut timbulah sebuah ide untuk membuat suatu produk penelitian dalam bidang fintech yang berbentuk design prototype Islamic crowdfunding.

\subsection{Tahap Diverge}

Tahapan ini peneliti dan tim membuat konsep design prototype Islamic crowdfunding yang dibuat sesuai dengan kebutuhan dan masalah yang telah diuraikan pada tahap understand. Konsep yang membedakan dari konsep produk yang sudah ada adalah terdapat pada akses nya. Pelaku UMKM perempuan yang ingin melakukan penggalangan dana untuk usahanya diharapkan bisa langsung akses di platform tidak perlu mencari seseorang yang merekomendasikan. Hal lain yang akan membedakan dengan produk sebelumnya adalah terkait dengan adanya sistem persetujuan user (pelaku UMKM perempuan) oleh supervisor (suami/orang tua/ saudara/ keluarga terdekat). Supervisor ini nantinya akan bertugas memberikan persetujuan dari setiap aktivitas user saat melakukan penggalangan dana di platform. Sebab dalam rancangan ini sasaran user adalah perempuan, maka dari itu rancangan yang dibuat juga harus memperhatikan fitrah perempuan dalam setiap aktivitas bermuamalah.

\subsection{Tahap Decide}

Setelah membuat konsep design prototype Islamic crowdfunding, selanjutnya melakukan pemilihan konsep rancangan. Gagasan ide yang telah didapatkan dari tahapan sebelumnya, kemudian dipilih untuk menentukan fokus pembuatan produk penelitian dan pengembangan. Pada tahap ini keputusan ditentukan bersama kelompok studi penelitian atau tim penelitian, seperti apa dan bagaimana produk nantinya dibuat.

\subsection{Tahap Prototype}


Pembuatan design prototype Islamic crowdfunding ini sampai tahapan low fidelity prototype. Low fidelity prototype mempunyai fungsi atau interaksi yang terbatas, lebih menggambarkan konsep perancangan dan layout, tidak memperlihatkan secara rinci operasional sistem. Mendemonstrasikan secara umum feel and look dari antar muka pengguna dan hanya menggambarkan konsep pendekatan secara umum, seperti pada Gambar 1.

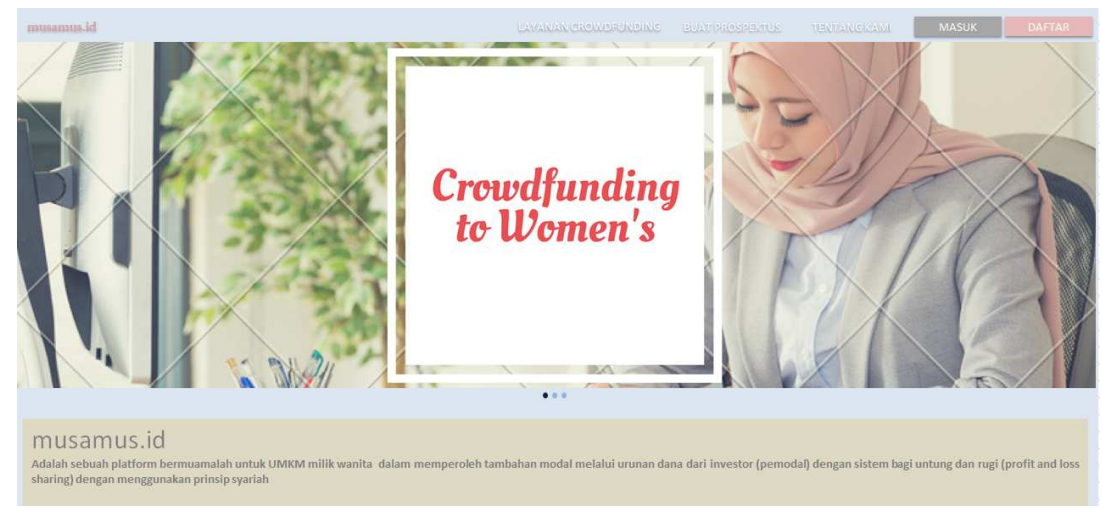

Gambar 1, Halaman pertama

Pada pembuatan prototype ini yang membedakan dengan produk yang sudah adalah adalah layanan pendaftaran terdapat dua pilihan, yaitu untuk pelaku UMKM perempuan dan pendana (investor). Hal ini sangaja dirancang seperti pada harapanya Gambar 2 agar dapat mempermudah para pelaku UMKM perempuan dalam mengakses permodalan tanpa harus menunggu rekomendasi dari pihak ketiga.

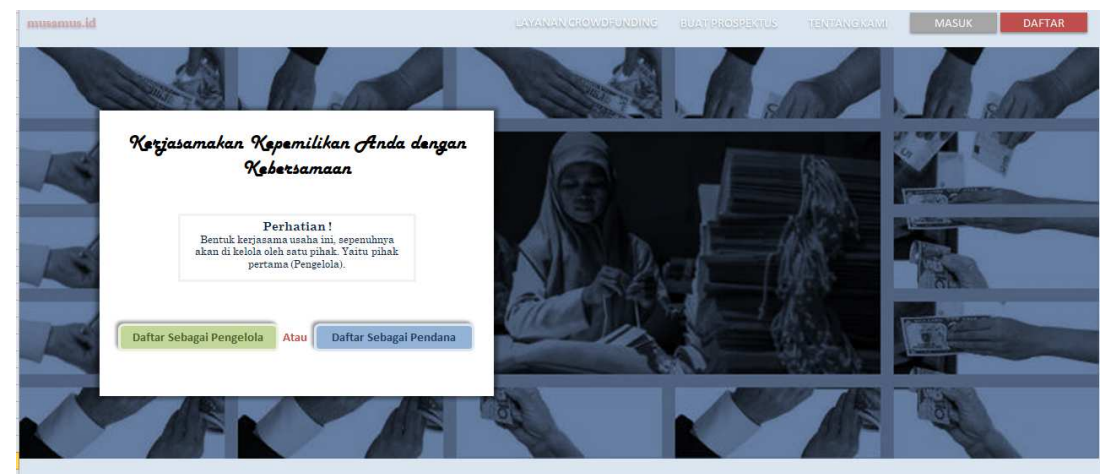

Gambar. 2. pendafataran sebagai pengelola atau pendana 


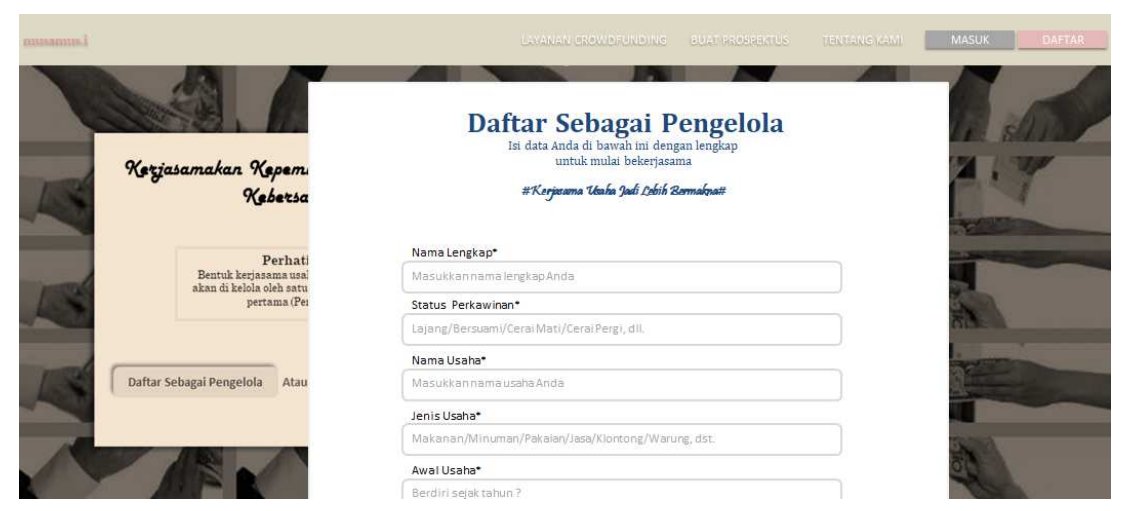

Gambar. 3. Formulir pendaftaran

Adapun yang membedakan lagi dari prototype ini nantinya adalah pada prosedur persetujuan saat user atau pelaku UMKM perempuan melakukan penggalangan dana pada platform. Pelaku UMKM perempuan dapat melakukan penggalang dana, apabila telah memeroleh persetujuan dari supervisore nya yaitu (suami/ orang tua/ saudara/ kelurga terdekat) seperti pada Gambar 4. Melibatkan seseorang yang punya hak atas keputusan si pelaku UMKM perempuan terhadap setiap aktivitas muamalah dengan tetap pada koridornya yaitu fitrah seorang perempuan berdasarkan syariat Nya. Terlebih saat ini memperhatikan aktivitas perempuan dalam bidang finansial sangat diperlukan, agar dapat terjaga ataupun terlindungi dari hal negatif. Hal ini disebabkan oleh perempuan itu lebih cenderung mudah sebagai sasaran tindak kejahatan. Kalimat perintah pada platform dapat ditunjukkan sebagai berikut:

"Form pendaftaran penggalangan Anda akan dikirimkan ke pada Supervisor untuk memberitaukan, memvalidasi dan menyetujui aktivitas Anda saat melakukan penggalangan dana di platform owners ini, masukkan alamat email suami/ orang tua/ saudara/ keluarga terdekat sebagai Supervisor Anda!"

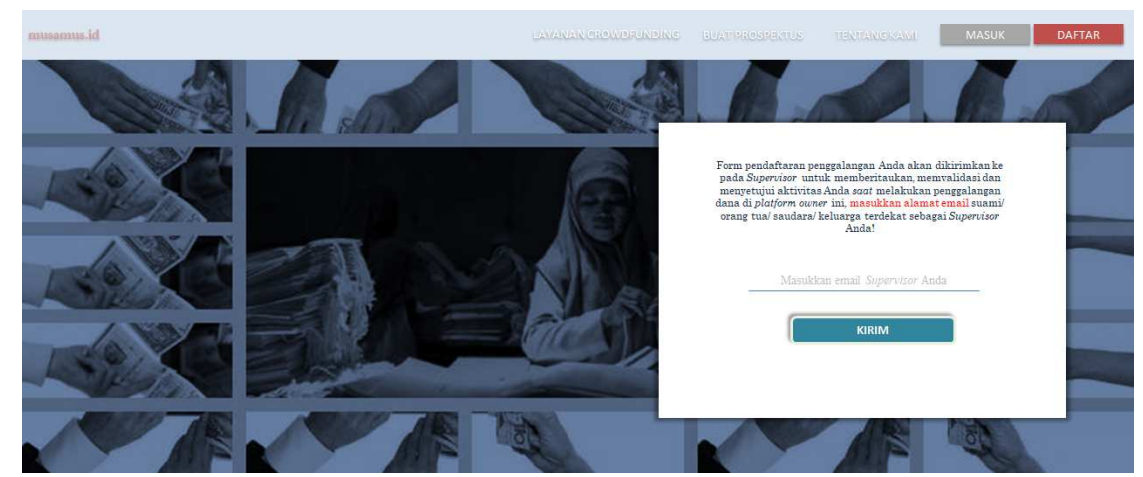

Gambar. 4. Tampilan perintah user untuk kirim email ke supervisor

\subsection{Tahap Validate}

Pada tahapan ini dilakukan tes rancangan dengan menunjukkan tampilan design prototype Islamic crowdfunding yang telah dibuat kepada ahli bidang untuk memperoleh hasil kelayakan produk penelitian sebatas pada User Experience tahap low fidelity prototype yaitu penilaian dari segi tampilan, warna, ukuran teks, gambar yang ditunjukkan melalui tampilan Microsoft excel. 


\section{Kesimpulan}

Kesimpulan yang dapat diambil dari penelitian ini adalah pembuatan rancangan prototype Islamic crowdfunding untuk pelaku UMKM perempuan dengan menggunakan metode design sprint lebih cepat dan terstruktur. Sehingga produk yang dirancang dapat dilakukan dengan mudah. Rancangan ini dibuat bukan hanya untuk keperluan peneliti, tetapi juga dipergunakan sebagai acuan peniliti lainnya terkait dengan topik yang sama.

\section{References}

[1]World Bank, "Women Entrepreneur in Indonesia a Pathway on Increasing Shared Prosperity" (The World Bank Office Jakarta, 2016), http://documents.worldbank.org/curated/en/738881467782741648/pdf/AUS5568-P147245PUBLIC-WomenEntrepreneursinIndonesia-1.pdf.

[2]UNDP, "Women's Entrepreneurship and Access to Finance Challenges and Opportunities of Women-Led Social Enterprises in Indonesia" (United Nations Development Programs, 2017), http://www.id.undp.org/content/dam/indonesia/2017/doc/INS-Gender\%20Report\%20Revisi.pdf.

[3]PricewaterhouseCoopers, "Women Unbound: Unleashing Female Entrepreneurial Potential," PwC, 2017, https://www.pwc.com/gx/en/about/diversity/womenunbound.html.

[4]Dr. Mushthaq Ahammed K, "Sharia Compliant Crowd Funding: An Alternative Optimal Platform For Funding MSMES," Kaav International Journal of Economics, Commerce \& Business Management 4/ISS-3/A13 (2017): 87-93.

[5]Paolo Pietro Biancone and Silvana Secinaro, "The Equity Crowdfunding Italy: A Model Sharia Compliant," European Journal of Islamic Finance 0, no. 5 (July 23, 2016), http://www.ojs.unito.it/index.php/EJIF/article/view/1797.

[6]Elmar Lins and Eva Lutz, "Bridging the Gender Funding Gap: Do Female Entrepreneurs Have Equal Access to Venture Capital?," International Journal of Entrepreneurship and Small Business 27, no. 2/3 (2016): 347, https://doi.org/10.1504/IJESB.2016.073993.

[7]UNDP, "Women's Entrepreneurship and Access to Finance Challenges and Opportunities of Women-Led Social Enterprises in Indonesia."

[8]Abdullah Saeed, "Islamic Banking and Interest: A Study of Prohibition of Interest and Its Contemporary Interpretation,” J.KAU: Islamic Econ Vol. 17, No. 2 (2004): 35-38.

[9]Mark Geiger and Seth C. Oranburg, "Female Entrepreneurs and Equity Crowdfunding in the US: Receiving Less When Asking for More," Journal of Business Venturing Insights 10 (November 2018): e00099, https://doi.org/10.1016/j.jbvi.2018.e00099. 